UCRL19895

Engineering Aralyses and Tests

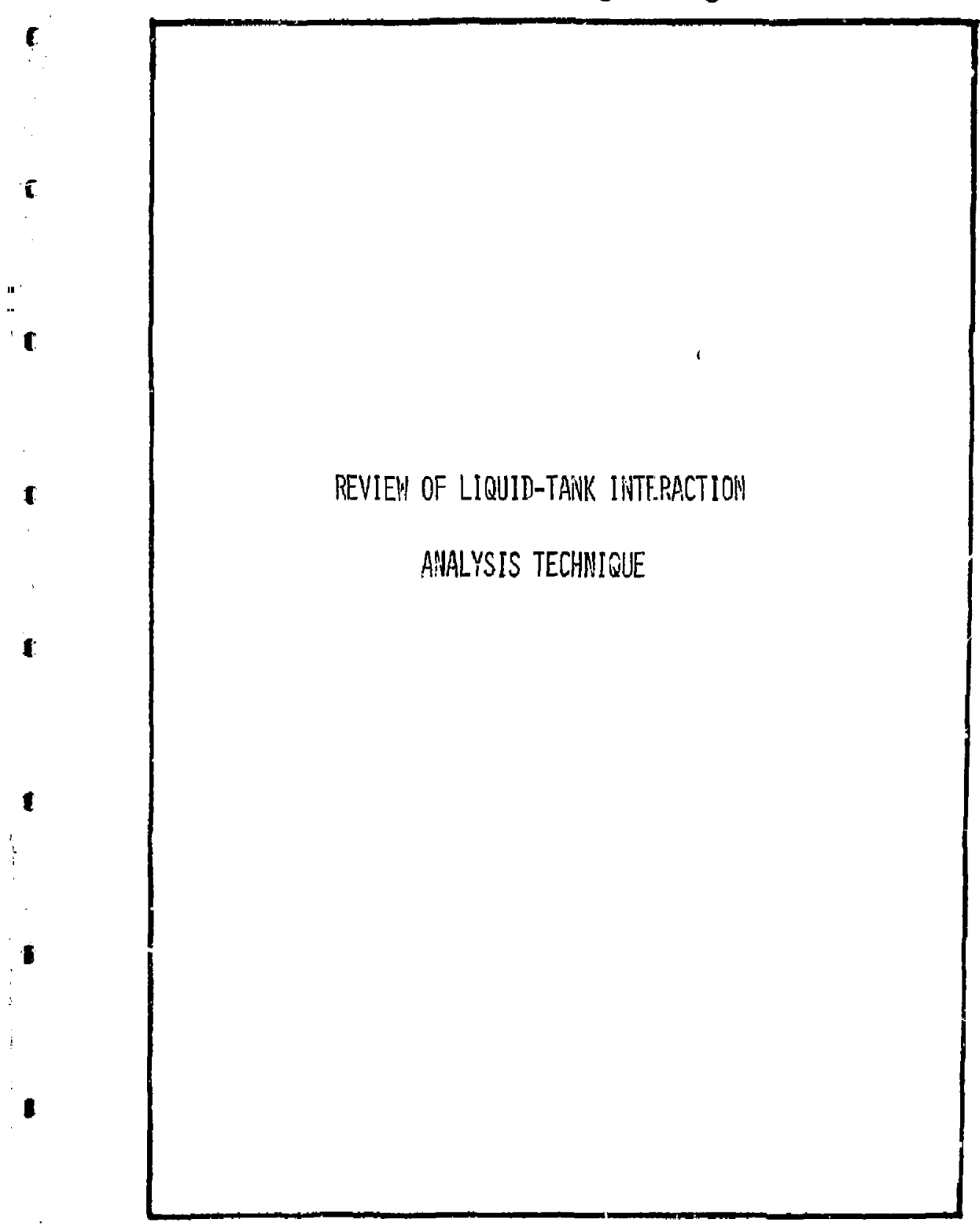

E.A.\&T. Co, Inc 4676 Admiralty Way, Marina del Rey, Ca90291
Project: 1016-1A

Date: DeceMBer 1977

MASTER

c

DISTRIBUTON OF SGUS DOCUMLNT IS UNLUMTEU 
46PG AOMIRALTY WRY

\section{SUITE 2U.}

MARINA DEL REY, CA, वOQ29,

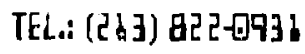

FORWARD

The special study carried out in this document was conducted under Purchase Oráer No. 7557303 with Lawrence Livermore Laboratory, University of California. Mr. Robert C. Murray of the Structural Mechanics Group, LLL, served as the technical representative for monitoring the project. Mr. Rajmond PEiez represented Engineering Analysis and Test Co., inc., as principal investigator.

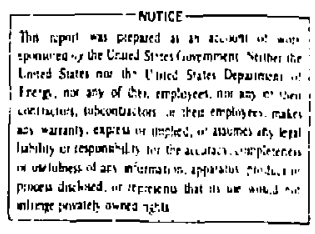




\title{
TABIJE OF CONTENTS
}

\author{
Abstract \\ 1.0 Introduction \\ 2.0 Summary and Conclusions \\ 3.0 Theory of Linear Dynamic Model \\ 4.0 Simplified Model of a Shallow Tank \\ 5.0 Complex Model \\ 6.0 Damping Effects \\ 7.0 Elastic Tank and Sloshing \\ 8.0 Wave Forces on Vertical Circular Columns \\ 8.1 Drag Force \\ 8.2 Virtual Mass Force \\ References \\ Figures
}


ABSTRACT

Based on a literature survey, various models of increasing sophistication and complexity are presented which might be used to assess the liquid tank interaction effects due to sloshing of contained high level radioactive liquid waste in storage tanks at the NFS site. In addition, the effects of liquid damping, tank bending modes, and nonlinearity of the slosining liquid are discussed.

The results of the survey indicate that due to the complexities encountered in adequate-y modeling the system, due to the approximations which must be made as regards the tank boundary conditions, and due to the assumptions which must be made reģarding the liquid waste dynamic character, the liquid tank interaction at NFS can not be a lequately theorecically modeled. It is therefore recommended that experimental scale model tests be performed to assess the effects of liquid tank interaction during seismic excitz'ion of the NFS waste tanks. 


\section{$1.0 \quad$ Introduction}

The objective of this study was to perform a literature survey to investigate and summarize the analytical models which might be used to assess the dynamic liquid tank interaction in high level liguid waste tanks at the Nuclear Fuel Services (NFS) site due to earthquake excitation. This information was to be used to refine the dynamic analyses of the existing NFS tanks to determine acceleration levels that could cause tank failure.

The available data on the dynamic modeling of the liquid-tank interaction phenomenon was noted to be marginal (see references 1 through 28). However, limited data on the observations of the response of liquid storage tanks has been found (16-18). Liquid tank interaction effects have been studied at the University of California, Berkeley by Ray Clough (2), and his associates and work is in progress on the investigation of offshore structural behavior by Ben C. Gerwick, Jr., J. Penzien and R.I. Wiegel (18). However, these studies are not yet complete, and the reports to date do not have any relevant 
information that is useful for our work at NFS.

Based upon the survey, a selected list of references on liquid-tank interaction was found and is presented in the references. Most of the references discuss approximations used to model and account for the interaction phenomena. The methodologies and modeling procedures described in the references are in general, based upon analytical studies with limited and incomplete experimental data. The work in progress at UC Berkeley is an exception, and the only significant work to date in the area of liquid-tank interaction phenomenon has been performed by NASA (1). MASA performed theoretical and experimental studies on the dynamic behavior of liquids in moring containers with applications to space vehicle technology.

Based upon the references, a set of modeling procedures has been developed which might be used to estimate the dynamic liquid pressures on the walls of tanks at NFS. These models are presented in the order of izcreasing sophistication. Included in this report are hrief discussions of the ron-linear effects and damping of the liquid motion. It is to be emphasized that to date the state of the art of dynamic liquidtank interaction modeling is confined to "fj.rst order" approximations. 


\subsection{Summary and Conclusions}

The literature survey conducted resulted in the presentation of various modeling formulations which might be employed to assess the relative effects of liquid tank interactions during seismic excitaitions. The state of the art of modeling liquid tank interactions was found to be confined to the generation of first order approximations.

The relative complexity of the NFS neutralized waste tank design corlbined with those complexities encountered in attenpting to reliably model the multiphase media of the tank contents (i.e., the supernate, slurry, and sludge layers) pose serious question as to the ability to adequately analytically model such efferts. It is therefore recommended that experimental scale modeling techniques be employed to assess this effect on the tank containment integrity under earthquake loadings.

\subsection{Theory of Linear Dynamic Moda1}

Ar exact solution to the general problem of analytically modeling fluid oscillations in a moving container is extremely difficult. Certain simplifying assumptions are generally employed. Since the interaction of liquid and the elastic tank is a complex problem, two sets of models are discussed; one in which the tank is assumed to be rigid, and another which accounts for the interactions. 
Some of the essumptions generally used in the development of molels are:

(i) For large tanks, the viscous forces are negligible compared to other forces except near boundaries;

(ii) The fluid is incompressible; and

(iii) The liquid free surface displacements and velocities are small enough to linearise the boundary conditions.

Using the cartesian coordinates $(x, y, z)$ located on the disturbed liguid surface with $x$ and $y$ axes in the plane of liquid surface and the $\mathrm{z}$ coordinate normal, the velocity in any simply connected region can be derived by taking the gradient of velocity potential $F(x, y, z)$

$$
\underline{Y}=\nabla \Phi
$$

or, in terms of the velocity components, $u, v$ and $w$ as

$$
\mathrm{u}=\frac{\partial \Phi}{\partial \mathrm{x}} \quad \mathrm{v}=\frac{\partial \Phi}{\partial y} \quad \mathrm{w}=\frac{\partial \phi}{\partial z}
$$

From Newton's second law for a particle in a nonviscous fluid,

$$
-\frac{1}{\rho}\left(\nabla p+\underset{\rightarrow B}{F_{B}}\right)=A
$$

where $\rho$ is the nass density

$p$ is the normal pressure

${ }_{\rightarrow}{ }_{B}$ is the boundary condition force vector, and

$\stackrel{A}{\rightarrow}$ is the acceleration vector.

Preserving the continuity of fluid (mass conservation), 
we have:

$$
\nabla \cdot \underline{Y}=0
$$

Equation 3.3 can be rewritten in the expanded form as

$$
\begin{aligned}
& \frac{\partial u}{\partial t}+v \frac{\partial u}{\partial x}+v \frac{\partial u}{\partial y}+v \frac{\partial u}{\partial z}=-\frac{1}{\rho} \frac{\partial p}{\partial x} \\
& \frac{\partial v}{\partial t}+u \frac{\partial v}{\partial x}+v \frac{\partial v}{\partial y}+w \frac{\partial v}{\partial z}=-\frac{1}{\rho} \frac{\partial p}{\partial y} \\
& \frac{\partial w}{\partial t}+u \frac{\partial w}{\partial x}+v \frac{\partial w}{\partial y}+w \frac{\partial w}{\partial z}=-\frac{1}{\rho} \frac{\partial p}{\partial z}-A
\end{aligned}
$$

Equations 3.4 and 3.5 are sufficient, once the boundary conditions are met, to determine the velocity components, and the pressure $p$, uniquely.

Using equations 3.1 and 3.4 , it is seen that $\Phi$ must satisfy

$$
\nabla^{2} \Phi=0
$$

where $\nabla$ is the Laplace operator. This equation can be converted to Bernoulli's law as

$$
\frac{\partial \Phi}{\partial t}+\frac{1}{\rho} p+g z=0
$$

where $g$ is the gravitational field. Thus, from equations 3.6 and 3.7 combined with boundary conditions, the velocity and pressure distributions can be computed. The moments and forces acting on the container may be found by appropriate integration of the pressures. For converience, the velocity potential may be written as $\Phi=\phi_{C}+\Phi_{l}$ where $\Phi_{C}$ is that of the container, and $\Phi_{1}$ is the liquid moving relative to the container. The linear boundary conditions are: 


$$
\frac{\partial \phi}{\partial n}=v_{n}
$$

at the container walls where $\partial / \partial$ n denotes differentiation in the direction normal to the surface of a rigid body in contact with the fluid, and $v_{n}$ is the common velocity of the fluid and boundary surface in the nornal direction. Combining the Bernoulli equation with the condition that the liquid must stay on the surface, the eauations fo: the free surface become

$$
\begin{aligned}
& \frac{\partial \Phi}{\partial t}+g z=-\frac{1}{\rho} g_{0} \\
& \frac{\partial z}{\partial t}-\frac{\partial \Phi}{\partial z}=0
\end{aligned}
$$

where $z=z(x, y, t)$ is the equation of free surface, and $p_{0}(x, y, t)$ is the surface pressure. By eliminating $z$ in equations 3.9 and assuming that $p_{0}=$ constant, we get

$$
\frac{\partial^{2} \Phi}{\partial t^{2}}+g \frac{\partial \Phi}{\partial z}=0
$$

The foregoing linear boundary value problem is solved by employing the method of separation of variables.

According to the theoretical development, a complete model for transverse sloshing must include an infinite number of oscillating spring-mass systems, one for each of the infinite number of normal sloshing. modes. 
An analogous reasoning is valid for rotational and longitudinal sloshing, as well. A detailed analysis of the theory and review of the experimental data show that:

(i) the magnitude of model parameters decreases with increasing mode number as shown in figures $3.1,3.2$, and 3.3 ;

(ii) the inclusion of the modes close to the excitation frequency adequately simulates sloshing;

(iii) the earthquake excitation energy is concentrated close to the lower end of the response spectrum, and that the fundamental mode of sloshing is often in the range of interest; and,

(iv) the participation Eactors for the higher harmonics are smaller than the fundamentals.

All three orthogonal directions and rotaticnal motion mlist be modeled to generate a first order approximation including the coupling between any two.

4.0 Simplified Model of a Shallow Tank

Analytical solutions are available fo: tanks of various shapes and for such complex problems as interaction between vibrations of liquid and deformations of the container walls, rotational motion of the liguid induced by translation of container, and so on (1-19). For small oscillations the velocity potential anc hracie the hydrodynamic pressure can be put in the form of a sum of eiger. functions times the cosine of $2 \pi f_{n} t$ where 
$\dot{f}_{n}$ is the natural frequency of vibration, and $t$ is time. This leads to a $n$-degree of freedom (DOF) dynamic system. For the simplified model, we sha1l contend with a one DOF system.

Consider a cyli:drical storage tank of radius $R$; containing an incompressible liquid of weight density $p$, filled to depth $h$, The total weight of che liquid is then

$$
W=\pi R^{2} h \rho
$$

A shallow tank defined as one in which

$$
\alpha=\frac{h}{\bar{R}} \leq 1,5
$$

is shown in figure 4.1. It consists of a mass of weight, $W_{1}$, moving with the rigid tank wall produing the impulsive force, and a spring mass of weight, $\mathbb{N}_{2}$, producing the convective force. These weights are given by

$$
\begin{aligned}
& w_{1}=\left\{\frac{\alpha}{\sqrt{3}} \tanh \left(\frac{\sqrt{3}}{\alpha}-\right)\right\} w=C_{4} W \\
& w_{2}=\left\{\frac{0.318}{\alpha} \tanh (1.84 \alpha)\right\} W=C_{6} \text { W }
\end{aligned}
$$

in which $C_{4}$ and $C_{6}$ as well as other values of $C$ to be defineâ have been termed hydrocynamic design constants.

The weights are located at heights that are derived on the basis of producing the correct moment about the 
base. The bending moment on a horizontal section just above the base is resisted by the tank she11. The equivalent heights needed to give this moment are given by

$$
\begin{gathered}
h_{1}=\frac{3}{8} h \\
h_{2}=\left\{1-\frac{\cosh (1.84 \alpha)-1}{1.84 \alpha \sinh (1.84 \alpha)}\right) h=c_{8} h
\end{gathered}
$$

The dynamic pressure distrubution on the bottom of the tank must be included in calculating the overturning moment that exists on a horizontal plane just below the base of the tank and is resisted by the foundation. If the same weights, $w_{1}$ and $w_{2}$, are used to define the problem, new equivalent heights (denoted by the superscript $\left.{ }^{\circ}\right)$ must be used to account for this bottom pressure. These heights are given by

$$
\begin{gathered}
h_{1}^{0}=\left\{\frac{1}{8}\left(\frac{4}{c_{4}}-1\right)\right\} h=c_{5} h \\
h_{2}^{0}=\left\{1-\frac{\cosh (1.84 \alpha)-2.01}{1.84 \alpha \sinh (1.84 \alpha)}\right\} h=c_{7} h
\end{gathered}
$$

The spring stiffness, $k$, is such that the period, $T$, of the oscillating liquid equals that of the spring-mass system. The period is given by

$$
T=\frac{2 \pi}{\omega}=2 \pi\left(\frac{R}{1.84 \mathrm{~g} \tanh (1.84 \alpha)}\right)^{\frac{1}{2}}=2 \pi\left(\frac{R}{g C_{1}}\right)^{\frac{1}{2}}
$$


in which $w=$ the frequency; and $g$ = the acceleration of gravity. As the liquid level lowers, o decreases and the period increases.

If the base of the tank is subjected to a onedimensional horizontal earthquake excitation, the maximum forces exerted on the rigid tank by the two masses are

$$
\begin{aligned}
& P_{1}=\frac{W_{1}}{g} A_{0} \\
& P_{2}=\frac{W_{2}}{g} A
\end{aligned}
$$

in which $A_{0}=$ the maximum ground acceleration; and $A=$ the maximum acceleration experienced by the sloshing mass that may be found from the response spectrum of the earthquake by using the period given in equation 4.9. If these forces are conservatively assumed to occur simultaneously, the maximum bending moment caused by the liquid is given by

$$
\mathrm{BM}-\mathrm{P}_{1} \mathrm{~h}_{1}+\mathrm{P}_{2} \mathrm{~h}_{2}
$$

Substituting for the quantities appearing in this equation results in the non-dimensional relationship

$$
\overline{B M}=\frac{(B M) g}{\rho R^{4} A_{0}}=\left\{\frac{3}{8} C_{4}+C_{6} C_{8}\left(\frac{A}{A_{0}}\right)\right\} \pi \alpha^{2}
$$

The overturning moment caused by the liquid is given by

$$
\text { OTM }=P_{1} h_{1}^{0}+P_{2} h_{2}^{0}
$$

or, after substitution 


$$
\overline{O T M}=\frac{(O T M) g}{\rho R^{4} A_{0}}=\left\{C_{4} C_{5}+C_{6} C_{7}\left(\frac{A}{A_{0}}\right)\right\} \pi \alpha^{2}
$$

The nondimensional bending and overturning moments given in equations 4.13 and 4.15 are plotted versus $n$ (in which $x \leq 1.5$ ) in Eigures 4.2 and 4.3 , respectively, for various values of $A / A_{0}$. In computing final values for bending and overturning moments, the tank weight, $W_{\mathrm{T}}$, should be accounted for $\mathrm{by}_{y}$ adding the term, $W_{T} A_{O} h_{T} / g$, to the values obtained for $B M$ and $0 T M$, in which $h_{T}$ is the height from the base to the center of gravity of the tank.

Alternatively, a model for sloshing can be developed using a mechanical pendulum analogy as depicted in figure 4.4. It consists of a pendulum corresponding to the fundamental natural frequency of sloshing. The model development is analgous to the spring-mass model described in the preceding section.

The pendulum $W_{3}$ is assumed to have no centroid moment of inertia (i.e., the pendulum is a point mass with a massless rod) and the fixed mass, $W_{4}$, is assumed to have a moment of inertia, $I_{0} \Phi_{0}$ and $n_{0}$ are the pitching and translation of the tank. The assumptions are: 
(i) linearized motions are considered, and that $\psi$ is small;

(ii) the sum of $m_{3}$ and $m_{4}$ is equal to the total mass of the tluid; and,

(iii) that $\psi$ is so small that the pendulum is always perpendicular to the free liquid surface.

The pendulum model parameters can be determined from analytical expressions for the sloshing forces and moments. The model parameters are

$$
\begin{aligned}
& L_{1}=\frac{R}{1.84} \cosh (1,84 \alpha) \\
& W_{3}=W\left\{\frac{1}{2.2 \alpha} \tanh (1.84 \alpha)\right\} \\
& w_{4}=w-w_{3} \\
& \ell_{1}=\frac{\mathrm{R}}{3.68} \operatorname{cosech}(3.68 \alpha) \\
& l_{0}=\frac{W}{2 W_{4}}\left(h-\frac{R^{2}}{h}\right)-\left(l_{1}+L_{1}\right) \frac{W_{3}}{W} \\
& I_{0}+W_{4} \ell_{0}^{2}+W_{3}\left(\ell_{1}^{*} \dot{L}_{1}\right)=I_{\text {rigid }}+W\left(\frac{h}{2}\right)^{2}-\frac{W R^{2}}{2} \\
& \text { where } I_{\text {rigid }}=W^{2}\left\{\frac{1}{12}\left(\frac{h}{R}\right)^{2}+\frac{1}{4}\right\}
\end{aligned}
$$

These model parameters can be used on equations 4.7 through 4.15 to obtain the bending moments and overturning moments due to slosining. (Note that the spring force is generated by gravity, and that $I_{I}$ is tuned for fundamental frequency.)

When a tank is excited in the transverse direction, a rotational wave is generated, and this can be modeled 
using a modified, conical pendulum model. Figure 4.5 describes a conical pendulum model for rotary sloshing in tanks. The model parameters are computed from equations 4.16 through 4.21 . It should be noted that the excitation of this mode is caused by the coupling between the translation and rotational modes.

A series of compound, coupled spring-mass and pendulum mass can be used to simulate sloshing to a second order level including the effects of rotation and translation of tanks. The spring-mass and pendulum parameters are obtained as before. The significant factor in this case is to locate and tune the springmass and pendulum models to simulate the appropriate lateral and transverse sloshing. The model parameters are computed from equations 4.1 through 4.21 .

A series of compound double pendulum models can be used to simulate the sloshing to a higher order. The concept is described in figure 4.6. The model parameters are obtained as described earlier.

As a complement to the transverse slosh models, a model for vertical sloshing can be developed. Developing an equivalent model for vertical sloshing, however, is considerably more difficult than for transverse sloshing because of the infinite number of possib]e 
liquid motions. A hypothetical model for the first antisymmetric mode, however, is shown in figure 4.7. The fixed mass, $\mathrm{m}_{\mathrm{o}}$, is supposed to duplicate inertia effects of the rigid body fluid motion and the pendulum is supposed to duplicate the sloshing mass of the liquid. The equation of motion for the pendulum to the third order is

$$
\ell_{1} \beta+\left(g-4 \omega^{2} x_{0} \cos 2 \omega t\right) B\left(1-\frac{1}{6} \beta^{2}\right)=0
$$

where $\beta=$ the pendulum amplitude. It should be noted that the equation is nonlinear and should simulate sloshing to good accuracy. The model parameters must be determined from experimental tests, especially, the plane of the pendulum's motion. The equation is dependent upon the imperfections on the actual system, and thus it cannot be idealized. It should be further noted that this model is good only for antisymmetric modes, and that a model that vibrates up and down comparable to that of transverse sloshing models must be developed for symmetrical mode simulation. 


\section{0 Complex Model}

As discussed earlier, a complete nodel must have an infinite number of spring-mass equivalents for each of the many sloshing modes. The complete model consists of a n-degree of freedom (DOF) spring and mașs models as shown in figure 5.1. The $n$-th natural frequency is given by

$$
\omega_{n}^{2}=\frac{k_{n}}{m_{n}}=\frac{2 \xi_{n} g}{d} \tanh \left(\frac{2 \xi_{n} h}{d}\right)
$$

where $k_{n}=$ stiffness, spring constant

$$
\begin{aligned}
m_{n} & =\text { mass } \\
\xi_{n}= & \text { zeroes of } J_{1}\left(\xi_{n}\right)=0, \text { the first order } \\
\text { Bessel function } & \\
d= & 2 R, \text { the diameter of the tank } \\
g= & \text { gravity } \\
h= & \text { liquid depth. }
\end{aligned}
$$

Also, the total mass and the center of gravity are unchanged, and are represented by

$$
\begin{aligned}
& m_{0}+\sum_{n=1}^{\infty} m_{n}=m_{t} \\
& h_{0}=\frac{1}{m_{0}} \sum_{n=1}^{\infty} h_{n} m_{n}
\end{aligned}
$$

and the model parameters for the $n$-th set of mass and springs are conputed from 


$$
\begin{aligned}
& k_{n}=m_{t}\left\{\frac{2 g}{h\left(\xi_{n}^{2}-1\right)} \tanh \left(2 \xi_{n} \quad \frac{h}{d}\right)\right\}^{2} \\
& m_{n}=m_{t}\left\{\frac{d}{\xi_{n} h\left(\xi_{n}^{2}-1\right)} \tanh \left(2 \xi_{n} \quad \frac{t^{2}}{d}\right)\right. \\
& h_{n}=\frac{h}{2}-\frac{d}{\xi_{n}} \tanh \left(\xi_{n} \frac{h}{d}\right) \\
& I_{0}+m_{0} h_{0}^{2}+\sum_{n=1}^{\infty} m_{n} h^{2}=c
\end{aligned}
$$

where $m_{0}=$ mass rigidly attached to the tank

$I_{0}=$ moment of inertia

$C=$ a constant and is determined from figure $\mathbf{5 . 2}$

$m_{t}=$ total liquid mass, and

$\mathrm{n}=$ subscript refers to the $\mathrm{n}$-th model values.

\subsection{Damping Effects}

All fluids exhibit a certain amount of resistance to motion. Because of viscous friction, a small portion of the energy of a sloshing liquid is dissipated during each cycle of motion. The exact form of the damping of a sloshing liquid in a moving tank is difficult to determine. However, because the energy dissipated due to sloshing is relatively small, it seems reasonable to model by equivalent linear viscous damping. Hence, the equations of motion are simplified, and are treated as a n-DOF system. The equations of motion could be uncoupled. and expressed in modal domain. 
Thus, one could postulate an equivalent viscously damped model. The damping ratio, however, must be obtained from experimental data and must be a function of viscosity of the fluid, geometry of container, baffles, etc.

For a linear viscously damped system, the loyarithmic decrement method defined as

$$
\delta=\frac{1}{n} \ln \frac{\text { (maximum amplitude for } 1-\text { st cycle) }}{\text { (maximum amplitude after n cycles) }}
$$

can be used to estimate modal damping ratios. Based upon the data presented in the NASA report, a curve relating damping ratic and normalized wave amplitude has been developed and is shown in figure 6.1. The test environment and references are shown in the figure, and the test liquid was water. An empirical relationship for calculating the damping coefficient as a function of liquid depth, amplitude, viscosity, surface tension, etc., was obtained in the form

$$
\begin{gathered}
\delta=4.98 \gamma^{0.5} \frac{1}{\mathrm{R}^{\cdot 75}} \frac{1}{\mathrm{~g}^{.25}}\left(1+\frac{0.318}{\sinh (1.34 \mathrm{~h} / \mathrm{r})} .\right. \\
\left.\left\{\frac{1-\mathrm{h} / \mathrm{R}}{\cosh (1.84 \mathrm{~h} / \mathrm{r})}+1\right\}\right)
\end{gathered}
$$


where $\gamma=$ kinematic viscosity

$R=$ tank radjus

$g$ = gravity

$h=1$ iquid depth

$\delta=$ logarithmic decrement of amplitude, For

large depth, the asymptotic value of the equation is

$$
\delta=4.98 \gamma^{-.5} \frac{1}{R^{.75}} \frac{1}{g^{.25}}
$$

However, work by others seems to indicate that the constant 4.98 is higher, and is equal to 5.23 for large depths. Thus, it is recommended that an average value of 5.0 be used for omputations.

Although most of the analytical model parameters have been developed assuming a perfect cylinder, the theory cas be applied to imperfect cylinders with baffles, rings, stiffners, etc. This is achieved by increasing the modal damping ratios. However, the magnitude of the damuing ratio must be determined from experimental dynamic tescs. Limited amounts of analytical expressions are available for simple geometric shapes.

Note that once $\delta$ is determined, the modal damping ratio, $\xi$, is computed from 


$$
\delta=\frac{2 \pi \xi}{\sqrt{1-\xi^{2}}}
$$

\subsection{Elastic Tank and sloshing}

The significant bending modes of large tanks usually occur at low frequencies, and are often close to the sloshing frequencies; therefore, mutual interaction between the two motions might be anticipated. The coupled, liquid-tank motion is determined by a Lagrangian formulation, taking the kinetic energy in the form

$$
T=\frac{3}{2} \iint_{i j} m_{i j} g_{i} g_{j} d x d y \text { and the }
$$

potential energy as

$$
v=\frac{1}{2} \iint_{i j} k_{i j} g_{i} g_{j} d x d y \text {, where }
$$

$g_{i}$ is the generalized coordinates of tank and liquid system. The Lagrangian equations can be used to derive the frequency equation. Assuming that only the bending motion of the tank is significant, i.e. $f(z)$ is sufficient to describe the (figure 7.1) mode shape of the tank, and $\tau(\gamma, \theta)$ is the shape of the liquid mode shape, the frequency equation is deduced for periodic motion as 


$$
w^{2}-w_{3}^{2}-\sum_{s=1}^{\infty} \quad \alpha_{3 s} \frac{\left(w^{2}-\Omega_{3 s}\right)^{2}}{w^{2}-w_{s+3}^{2}}=0
$$

The subscript 3 and $s+3$ correspond to the generalized displacements, $g_{3}(t) f(z)$ denoting bending and $g_{s+3}(t) \tau(n, \theta)$ denoting the s-th sloshing mode. Also, the following had been assumed:

$$
\begin{aligned}
& w_{3}=\left\{\frac{\bar{m}_{e^{2} e}+\bar{k}_{3,3}}{\bar{m}_{e}+\bar{m}_{3,3}}\right\} \quad \begin{array}{l}
\text { uncoupled bending } \\
\text { frequency, }
\end{array} \\
& w_{s+3}=\frac{\left.\bar{k}_{s+3, s+3}\right\}^{\frac{1}{2}}}{\bar{m}_{s+3, s+3}} \quad \begin{array}{l}
\text { uricoupled sloshing } \\
\text { frequency, }
\end{array} \\
& \Omega_{s}=\frac{\bar{k}_{3, s+3}}{\bar{m}_{3, s+3}} \quad \begin{array}{l}
\text { coupling coefficients, } \\
\text { static }
\end{array} \\
& \alpha_{3 s}=\frac{\bar{m}_{3, s+3}^{2}}{\bar{m}_{s+3, s+3}\left(\bar{m}_{e}+\bar{m}_{3,3}\right)} \quad \begin{array}{l}
\text { coupling } \\
\text { coeificients, } \\
\text { dynamic }
\end{array}
\end{aligned}
$$

where $\bar{m}_{\mathrm{e}}=$ effective tank mass

$$
w_{e}=\text { effective resonant bending Erequency, and }
$$
the bars indicate normalization by the total liquid mass.

The equation 7.2 has an infinite numier of roots for the coupled bending and sloshing frequencies and the equation must be solved using some engineering judgement as to what are insignificant and negligible, 
and at best solved by numerical techniques. Figure 7.2 shows the numerical solution of equation 7.2 for the case of a simply supported tank, plotted as the percent increase in bending frequency due to coupling $\left(w-w_{3}\right) / w_{3}$ versus tank fineness ratio (1/d) for various depths of liquid. (This is for assumed mode shape shown in figure 7.1). Theoretical and experimental resonant frequency variation with liquid depth for simply supported tanks are shown in figures 7.3 and 7.4 .

A complement development for the breathing mode, corresponding to figure 7.5 wan be ceveloped. The results are well described by figure 7.6 for freely supported tanks in which the normalized nondimensional frequency is

$$
\sqrt{v}=f_{m n} 2 \pi a\left(\frac{\rho_{5}\left(1-v^{2}\right)}{E g}\right\}^{\frac{1}{2}}
$$

where $f_{m n}$ is the natural frequency of $m, n$-th mode $\lambda_{m}=m a / 1$, the axial wave length factol l. = height of tank, $\alpha=h / a$, ratio of tank thickness to mean radius a. In most of the analyses only the first few modes need to be considered. Figure 7.7 compares the experimental and theoretical relationships. It should be recognized that the above formulae are all used to estimate the natural frequencies of various modes, and one nust 
then determine the equivalent spring-mass, perdulum, or combination to include in the finite element model.

\subsection{Wave Forces on Vertical Circular Columns}

The force due to waves on vertical column is a combination of drag force and virtual mass force.

\subsection{Drag Eorce}

To obtain the value of the drag farce, a design wave is chosen. For this purpose the largest possible wave height, based on water (1iquid) depth is determined from figure 8.1. Next, the height of the wave crest elevation is estimated. (figure 8.2)

Having the above information the maximum drag force is computed in the following manner. First, the water particle velocities under the wave crests may be estimated from:

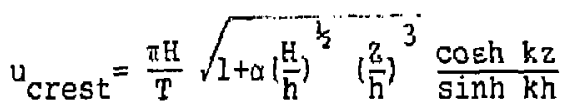

This equation has been computed for four elevations of $z=0,0.5 h, h$ and $h_{c}$. The results of the computation are compiled in figures $8.1 .1,8.1 .2$, and 8.1.3 in a form of $u T / \pi$ in versus $H / h$ with a parameter of $\mathrm{h} / \mathrm{L}_{\mathrm{A}}$, 
The drag force is obtainea by substituting the above velocities into:

$$
\left(F_{D}\right)_{\max }=\frac{\omega}{2 g} C_{D} D \int_{0}^{h} u^{2} d z=\omega C_{D} D H^{2} K_{D}
$$

where $k_{D}=$ nondimensional factor for maximum drag force. The moment of the maximum drag force is given by:

$$
\left(M_{D}\right)_{\max }=\frac{\omega}{2 g} C_{D} D \int_{0}^{h} \mathrm{C} \quad u^{2} z d z=C_{D} D H^{2} K_{D} S_{D}
$$

where $S_{D}=$ arm length of maximum drag force measured from the bottom of the tank. The coefficients $K_{D}$ and $S_{D}$ are computed with the following equations:

$$
\begin{aligned}
& k_{D}=\frac{\sinh 2 k h_{c}}{16 \sinh 2 k h} \\
& S_{D}=h \frac{G_{1}+A G_{2}}{c F_{1}+A F_{2}}
\end{aligned}
$$

where:

$$
\begin{aligned}
& A=\alpha\left(\frac{H}{h}\right)^{\frac{k}{2}} \frac{h_{c}}{\left(\frac{c}{h}\right)^{3}} \\
& F_{1}=1+\frac{2 k h_{c}}{\sinh 2 k h_{c}} \\
& F_{2}=1+\frac{k h_{c}}{2 \sinh 2 k h_{c}}+\frac{3}{2\left(k h_{c}\right)^{2}} 2\left\{1-\frac{k h_{c}}{\tanh 2 k h_{c}}-\frac{\tanh k h_{c}}{2 k h_{c}} c\right\} \\
& G_{1}=I+\frac{k h_{c}}{\operatorname{sinh2kh_{c}}-\frac{\tanh k h_{c}}{2 k h_{c}} c}
\end{aligned}
$$




$$
\begin{gathered}
\mathrm{G}_{2}=1+\frac{2 k h_{c}}{5 \sinh 2 k h_{c}}+\frac{1}{\left(k h_{c}\right)^{2}}\left\{3-\frac{2 k h_{c}}{\tanh 2 k h_{c}}\right\} \\
\left.+\frac{3}{2\left(k h_{c}\right.}\right)^{-4}\left\{1+\frac{2 k h_{c}}{\tanh 2 k h_{c}}\right\}
\end{gathered}
$$

The computation of these equations has been carried out for various values of $h / L_{A}$ and $H / h$ so as to yield the design diagrams for $K_{D}$ and $s_{D} / h$. the results are compiled in figures 8.1 .4 and 8.1 .5 . The arag coefficient $C_{D^{\prime}}$ is taken to be 1.0 for columns of circular section.

\subsection{Virtual Mass Force}

To compute the virtual mass force, the water particle accelerations of small amplitude waves are employed here as the first approximation. The water particle accelerations of small amplitude waves have the following maximum values at the time when the water surface crosses the mean water level.

$$
\left(\frac{\partial u}{\partial t}\right)_{\max }=\frac{2 \pi^{2} H}{T^{2}} \frac{\cosh k z}{\sinh k h}
$$

This acceleration has been calculated for points of three elevations $2=0,0.5 \mathrm{~h}$, and $h$ and is compiled in figure 8.2.1 which shows the non-dimensional acceleration, $\left(\frac{\partial u}{\partial t}\right)_{\max } T^{2} / H$ as a function of relative depth $h / L_{A}$. 
The maximum virtual force is then computed from:

$$
\left(F_{M}\right)_{\max }=\frac{w}{g} C_{M} \frac{\pi D^{2}}{4} \int_{0}^{h}\left(\frac{\partial u}{\partial t}\right)_{\max } d z=\omega C_{M} D^{2} H K_{M}
$$

where $\mathrm{K}_{\mathrm{K}}=$ non-dimensional factor for maximum virtual mass

$$
\text { force }=\left(\frac{\pi}{8}\right) \tanh k h
$$

The moment of this maximum virtual mass force is also obtained by:

$$
\left(M_{M}\right)_{\max }=\frac{\omega}{g} C_{M} \frac{\pi D^{2}}{4} \int_{0}^{h}\left(\frac{\partial u}{\partial t}\right)_{\max } z d z=\omega C_{M} D^{2} H K_{M} s_{M}
$$

where $s_{M}=$ arm length of maximum virtual mass force measured from the bottom of the tank = $h\left\{1-\frac{1}{\mathrm{kh} \sinh \mathrm{kh}}(\cosh k h-1)\right\}$

The factors $K_{M}$ and $s_{M}$ have been computed and are compiled in figures 8.2 .2 and 8.2 .3 as functions of the relative depth, $h / L_{a}$. The virtual mass coefficient, $C_{M}$, for circular column is taken to be 2.0 . The total wave force may be estimated with:

$$
F_{T}=\left(F_{D}\right)_{\max } \cos ^{2} \frac{2 \pi t}{T}+\left(F_{M}\right)_{\max } \sin \frac{2 \pi t}{T}
$$

with the maximum drag force computed by equations 8.1.2 and 8:2.2. The total moment may also be estimated with equation 8.2 .4 in cooperation with equations 8.1 .3 and 8.2.3. The maximum values of the total force and its moment is evaluated as follows: 


$$
\begin{aligned}
& \text { for }\left(F_{M}\right)_{\text {max }}{ }^{2} 2\left(F_{D}\right)_{\text {max }} \\
& \left(F_{T}\right)_{\text {max }}=\left\langle F_{M}\right\rangle_{\text {max }} \text { at } t=-T / 4 \\
& \text { for }\left(F_{M}\right)_{\max } \leq 2\left(F_{D}\right)_{\text {max }} \\
& \begin{array}{l}
\left(F_{T}\right)_{\max }=\left(F_{D}\right)_{\max }+\frac{\left(F_{M}\right)_{\max ^{2}}}{\frac{4\left(F_{D}\right)_{\max }}{2}} \\
\text { at } t=\frac{T}{2} \sin ^{-1}=\left\{\frac{\left(F_{M}\right)_{\max }}{2\left(F_{D}\right)_{\max }}\right\}
\end{array}
\end{aligned}
$$

It should be mentioned that the values of $C_{D}$ and $C_{M}$ are the most conservative values chosen from a set of experimental data. 
REFERENCES

1. "The Dynamic Behavior of Liquids in Moving Containers with Application to Space Vehicle Technology", Ed. by H. Norman Abramson, prepared under contract no. NASr-94 (07) by the Southwest Research Institute for NASA, 1966, NASA-SP-106.

2. Clough, R.W. and Clough, D.P., "Observation of Fluid-Stucture Interaction in Two Liquid Filled circular Cylindrical Shells Subjected to Earthquake Excitation", Presented at 1976 SESA Spring Meeting, Silver Spring, Maryland, May 9-14, 1976 .

3. Epstein, Howard I., "Seismic Design of Liquid-Storage Tanks", ASCE, Sept. 1976, vol. 102, ST9, pp. 1659-1673.

4. Housner, G.W., "The Dynamic Behavior of Water Tanks", Bulletin Seismological Society of America, vol. 53, no. 1, Feb. 1963.

5. Housner, G.W., "The Dynamic Pressures on Accelerated Fluid Containers", Bulletin Seismological Society of America, vol. 47, no. 1 , Jan. 1957 .

6. Hoskins, L.M. and Jacobsen, L.S., "Water Pressure in a Tank Caused by Simulated Earthquake", Bulletin Seismological Society of America, vol. 24, 1934.

7. Jacobsen, I.S., "Impulsive Hydrodynamics of Fluid Inside a Cylindrical Tank and of Fluid Surrounding a Cylindrical pier: Bulletin of Seismological Society of America, vol. 39, no. 3, July 1949, pp. 189-204.

8. Jacobsen, I.S. and Ayre, R., "Hyrodynamic Experiment; with Rigid Cylindrical Tanks Sub,ected to Transient Motions", Bulletin of Seismological Society of America, vol. 41, no. 4, 0ct. 1951, pp/ 313-346.

9. "P:opellant Slosh Loads", NASA-5P-8009, prepared by Langley Research Center, NASA, Aug. 1968.

10. Ifirm, M. and Bratu, C., "The Effect of Seismic Action on the Dynamic Behavior of Elevated Water Tanks", Proc. of the International Association of Earthquake Engineering, 4th World Conference on Earthquake Engineering, Santiago, Chile, 1964, section $\mathrm{B4}$, pp. 127-142.

11. Goda, Yoshimi, "Wave Forces on a Vertical Circular Cylinder: Experiments and a Proposed Method of Wave Force Computation", For Port and Harbour Technical Research Institutue, Japan,

$\therefore$ Aug. 1964. 
12. Shaaban, S.H, and Nash, W.A., "Finite Element Analysis of a Seismically Excited Cylindrical Storage Tank, Ground Supported and Partially Filled with Liquid", Dept. of Civil Engineering, University of Mass., Amherst, 1976.

13. Cooper, R.M., "Dynamics of Liquids in Moving Containers", ARS Journal, vol. 30, Aug. 1960, pp. 725-729.

14. Firth, D., "The Vibrations of a Distorted Circular Cylinder Containing Liquid", 3rd Conference on Structura] Mechanics in Reactor Technology, London, Sept. 1975, sec. F 2/10.

15. Hatano, T., "An Examination on the Resonance of Hydrodynamic Pressure During Earthquakes Due to Elasticity of Water", Transactions of Japan Society of Civil Engineers, 129, 1966.

16. Newmark, H.M. and Rosenbleuth, E., "Fundamentals of Earthquake Engineering", Prentice-liall, N.J., 1971, part I, chapter 6 .

17. Housner, G., "Dynamic Analysis of Fluids in Containers Subjected to Acceleration", Nuclear Reacturs \& Earthquakes, TID-7024, VSAEC, 1969.

18. Wiegal, R.I., ed., "Earthquake Engineering", Prentice-Hall, N.J., 1970.

19. Chopra, A.E., "Hyrodynamic Pressures on Dams During Earthquakes", Proc. ASCE, 93 (EM6), 205-223, 1967.

20. Flores, A., et. al., "Hydrodynamic Pressures Generated by Vertical Rarthquake Component", Proc. of Fourth World Conference on Earthquake Engineering, Santiago, Chile, 2, $13-14,25-36$.

21. Nath; B., "Hydrodynamic Pressures on Arch Dams During Earthquakes", Proc. of Fourth world Conference on Earthquake Engineering, Santiago, Chile, 2, B-4, pp. 97-105, 1969.

22. Bratu, C., "Hydrodynamic Action on Water Tanks Due to Eazthquakes", 3rd Symposium on Earthquake Engineering, held at Roorkee, India, Nov: 1966 .

23. Hanson, R.D. ." "Behavior of Liquid Storage Tanks", The Great Alaska Earthquake of 1964, National Academy of Science, vol. 7, 1973; pp. 331-339.

24. Rinne, J.F., "Oil Storage Tanks", USS Coast \& Geodetic Survey, Environmental Sciences Services Administration, Alaska, Earthquake of 1964 and Aftershocks, vol. IIA, pp. 245-252. 
25. Shepherd, R., "The Seismic Response of Elevated Water Tanks Supported on Cross Braced Towers", Proc. of the 5th World Conference of Earthquake Engineering (WCEE), Rome, Italy 1974, vol. I, pp. 640-649.

26. Jennings, Paul C., "Damage to Storage Tanks", Engineering Features of San Fernando Earthquake of Feb. 1971, Calif. Institute of Technology, June 1971.

27. "The Force Exerted by Surface paves on Piles", Petroleum Transactions, American Institute of Mechanical Engineer Ing, $189,1950,149-154$.

28. Veletses, "Seismic Effects in Flexible Iiquid Storage Tanks", Proc. of the 5th World Conference on Earthquake Engineering, Rome, 1974, 1, 630-640. 


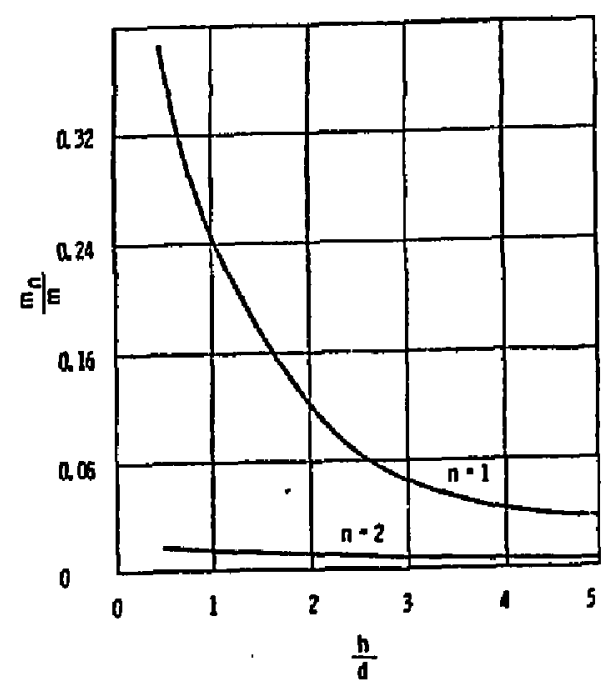

Fig. 3.1-Ratio of modal masses to cylindrical tanks'

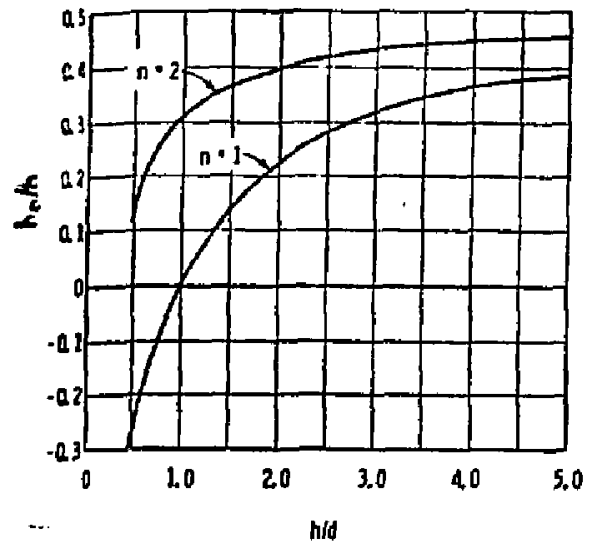

Fig. 3.2-Location and magnitude of modal masses for cylindrical tanks'

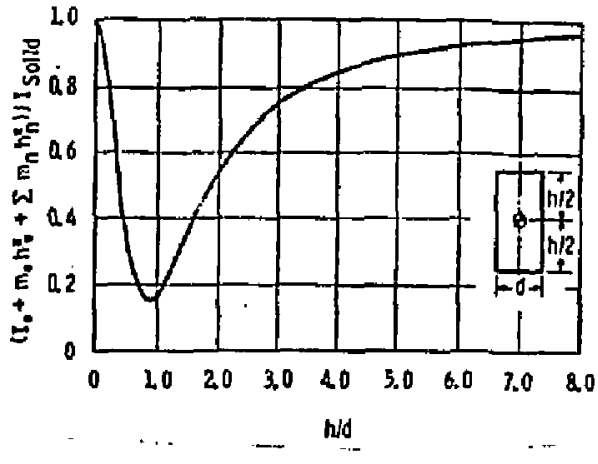

Fig. 3.3-Ratio of effective liquid to rigid liquid moment of inertia for cylindrical tanks' 


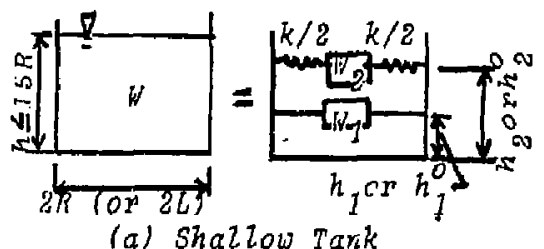

Fig. 4.1-Mathematical Models'

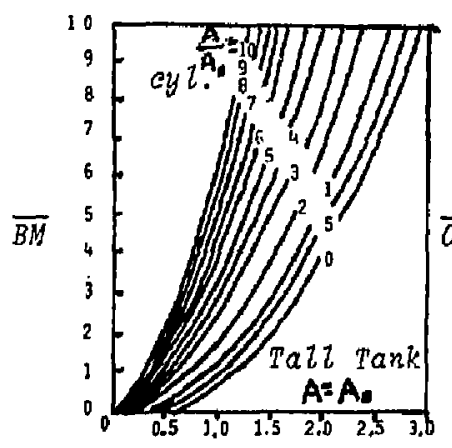

Fig. 4.2-Mondimensional Bending Moment for Cylindrical Tank

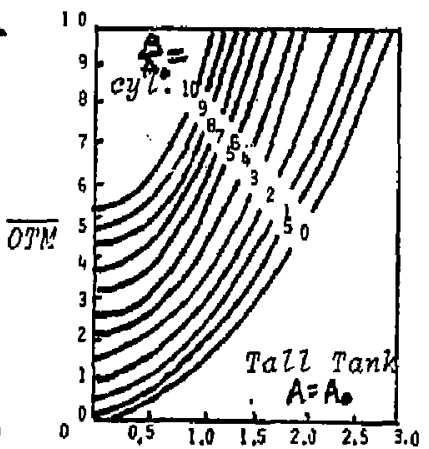

Fig. A.3-Nondimenstonal Overturning Moment for Cylindrical Tank' 


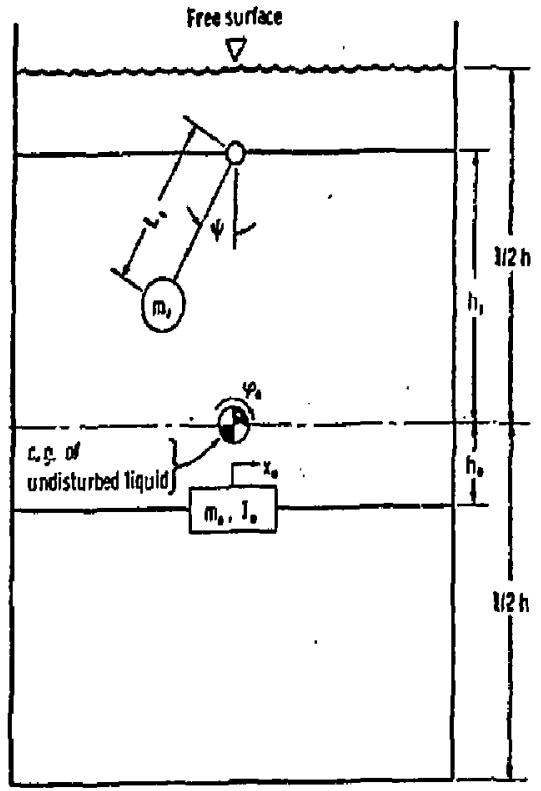

Fig. 4.4-Model with onel sloshing mass

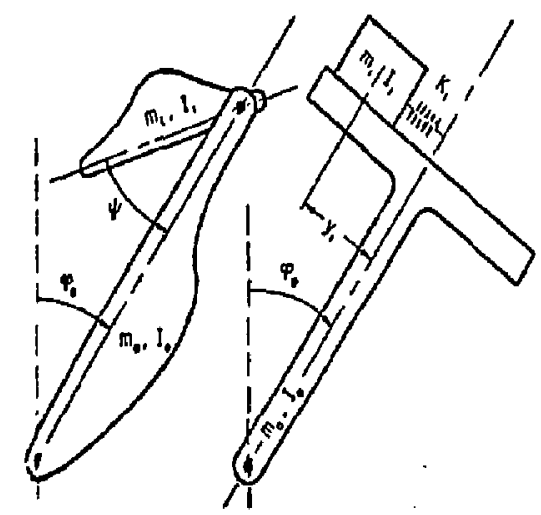

Fig. 4.6-Compound doublependulum mechanical models for long shallow rectangular tanks'

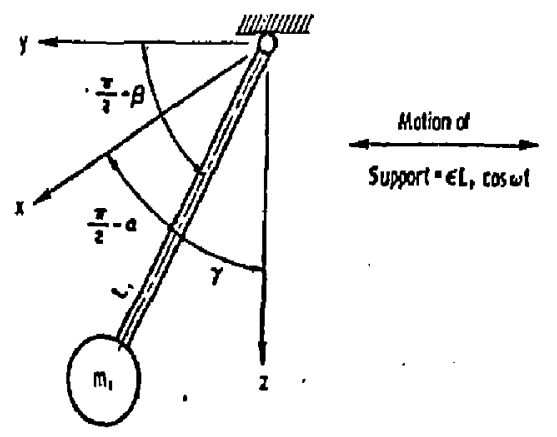

Fig. 4.5-Conical-pendulum model for rotary sloshing

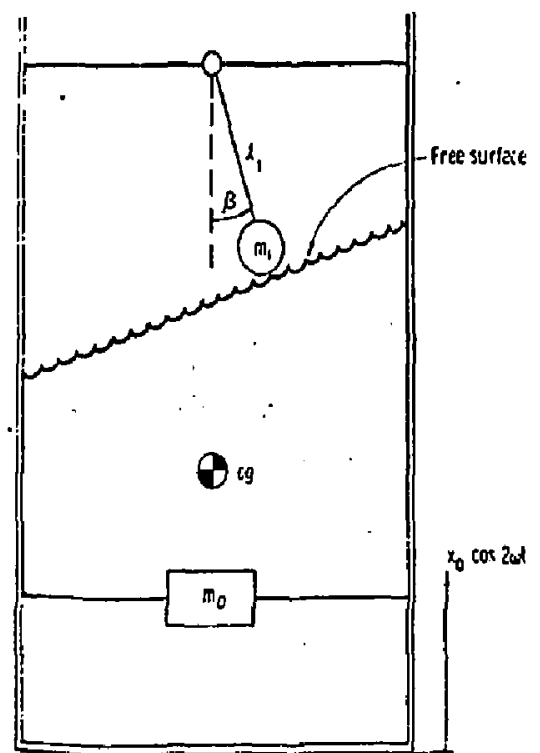

Fig. 4.7-Equivalent mechanical model for antisymanetric vertical sloshing. 


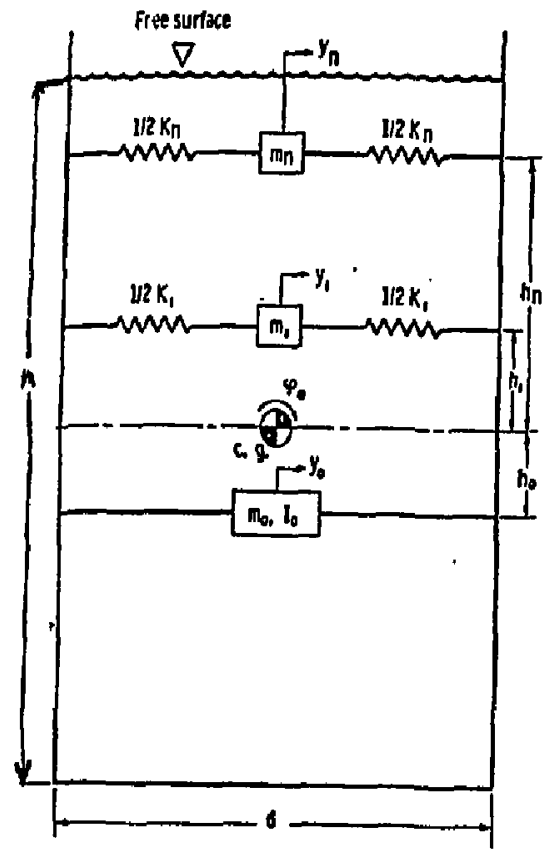

Fig. 5.1-Complex mechanical model for cylindrical tanks' 


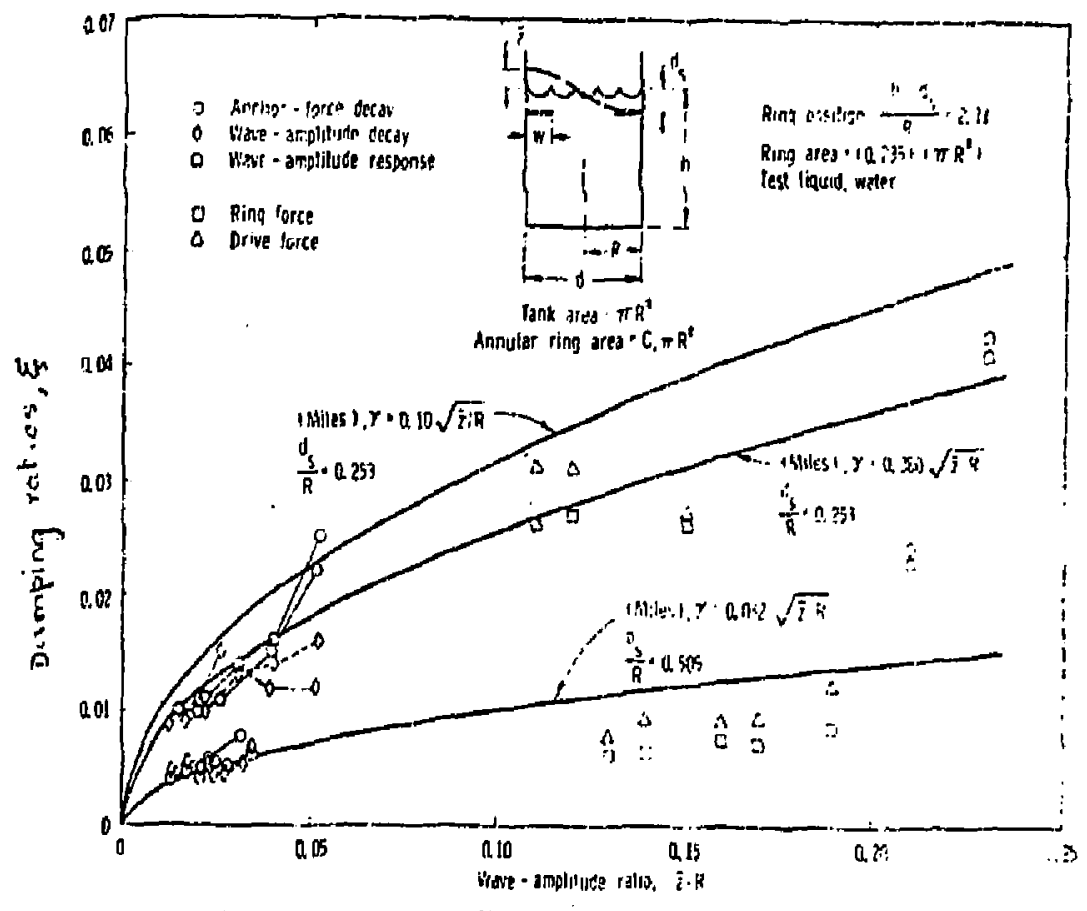

Fig. 6.1-Damping ratios for an annular ring in a cylindrical tank as obtained by various methods' 
C

C

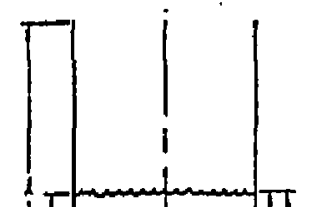

C

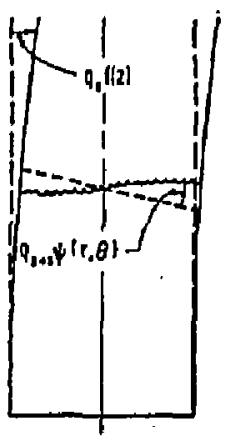

(b) Displaced condition

(a) Equilibrium condition

Fig. 7.1-Coordinate s"stem for bending tank containing a liquid.'

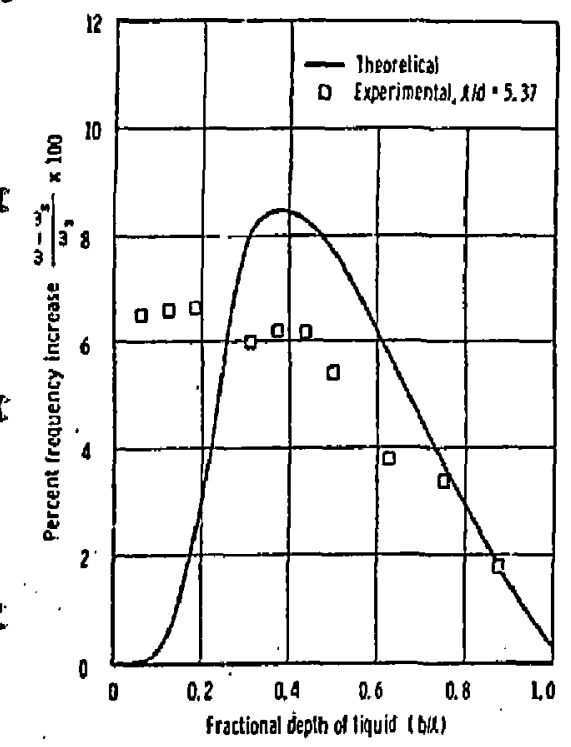

Fig. 7.3-Theoretical and experimental percent increase in resonant bending frequency versus liquid depth in simply supported tanks!

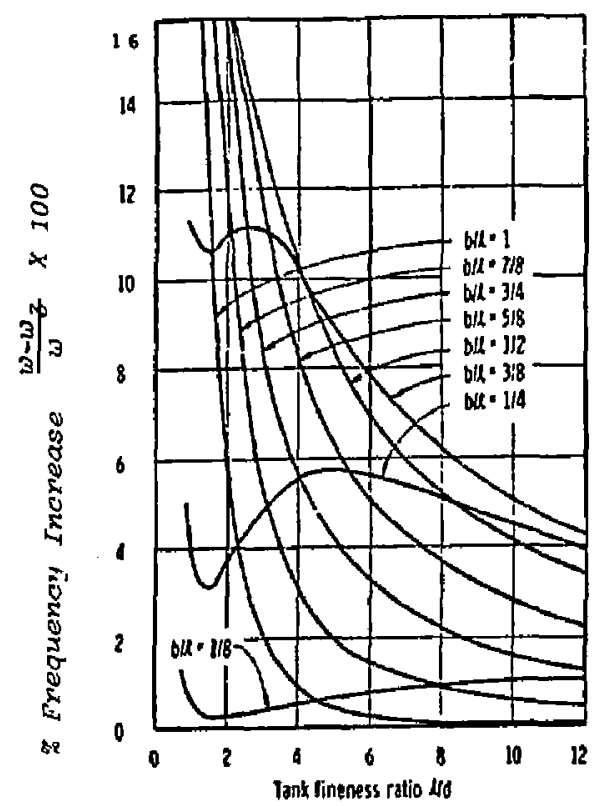

Fia. 7.2-Theoretical percent increase in re': jnant bending frequency due to free surface effects in simply supported tanks"

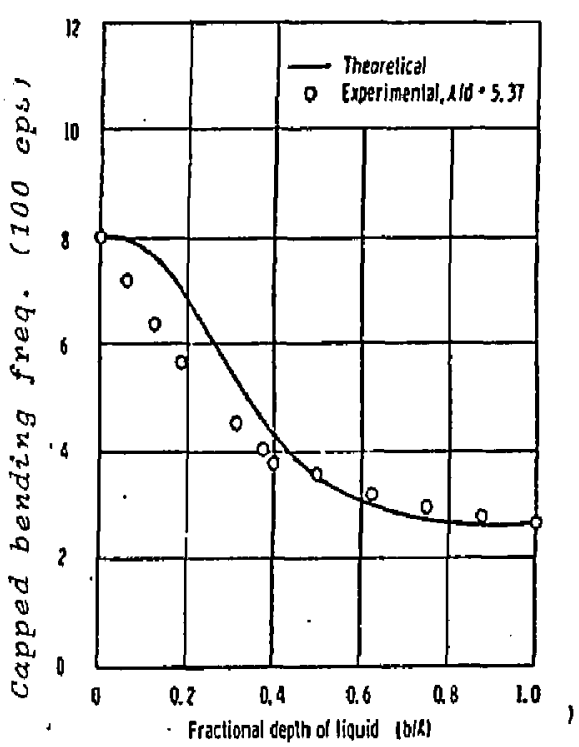

Fig. 7.4-Theoretical and experimental capped resonant bending frequency variation with liquid depth for simply supported tanks' 

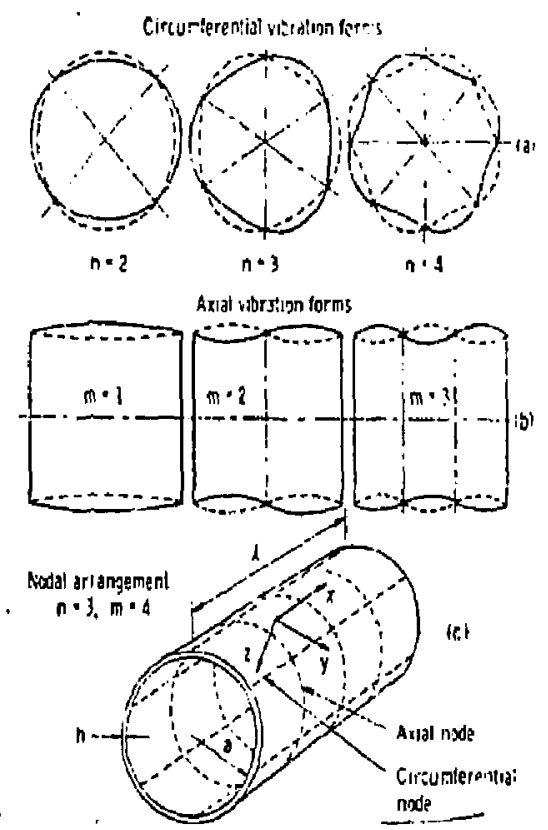

Fig. 7.5-Forms of vibration of thin cylinders vith freely supported ends'

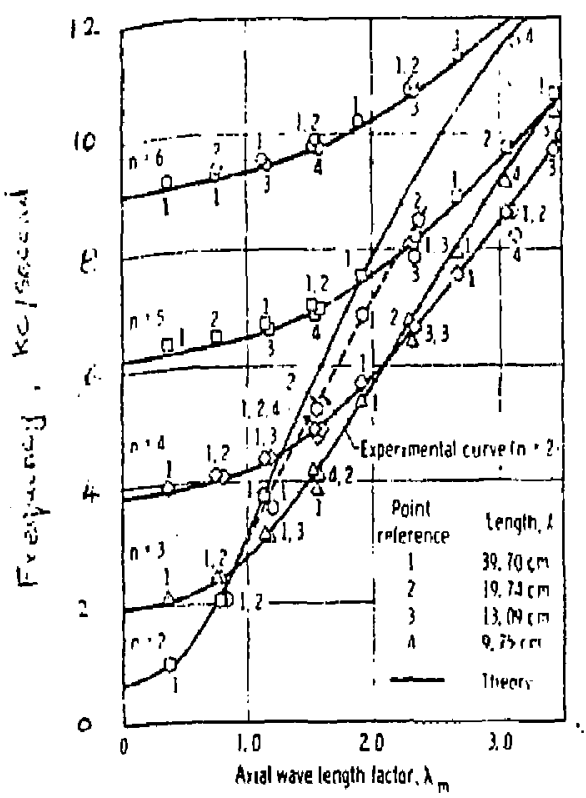

Fig. 7.7-Natural frequencies of empty cylinders' 


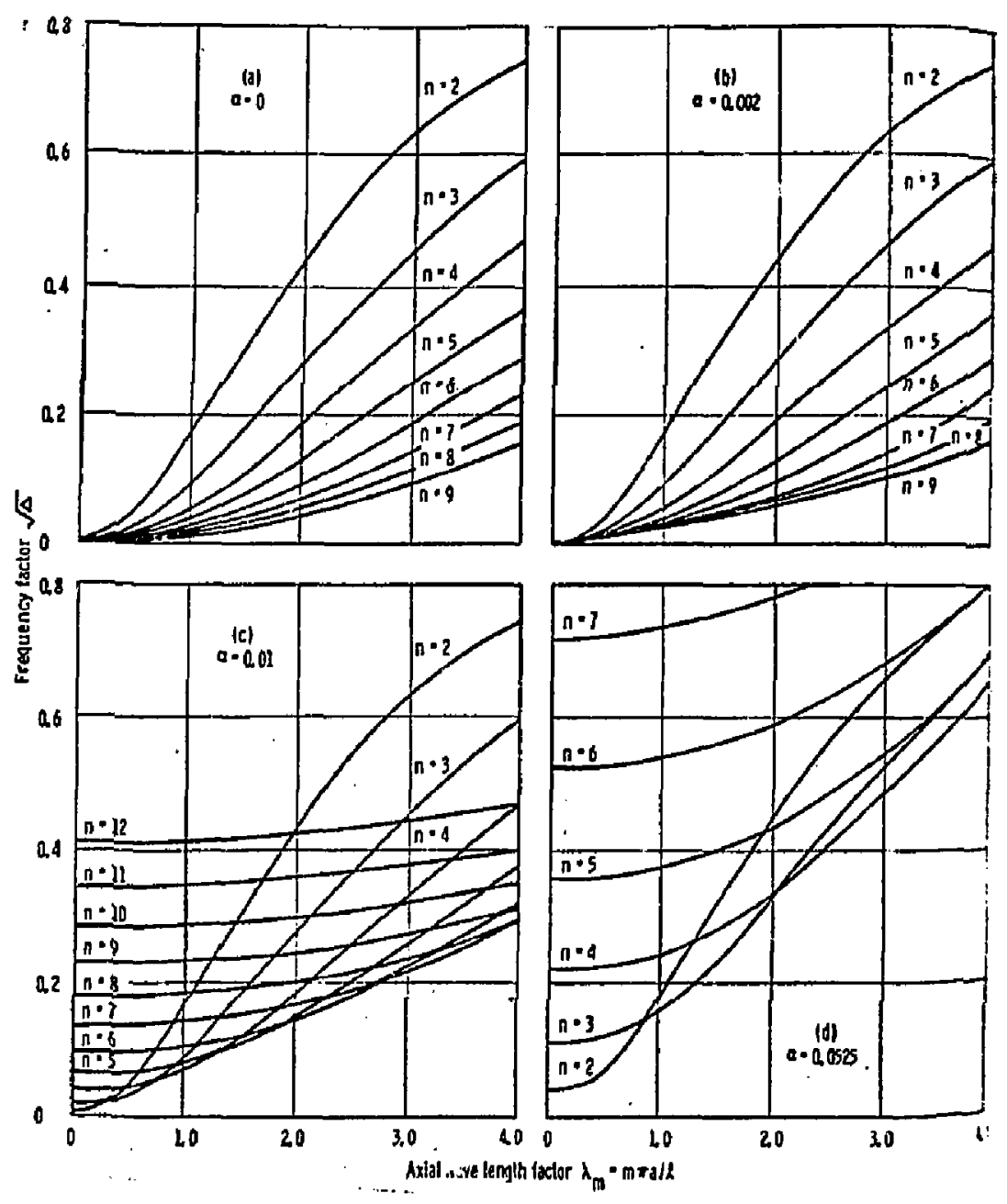

Figure 7.6-Theoretical frequency curves for cylinders with freely supported ends' 


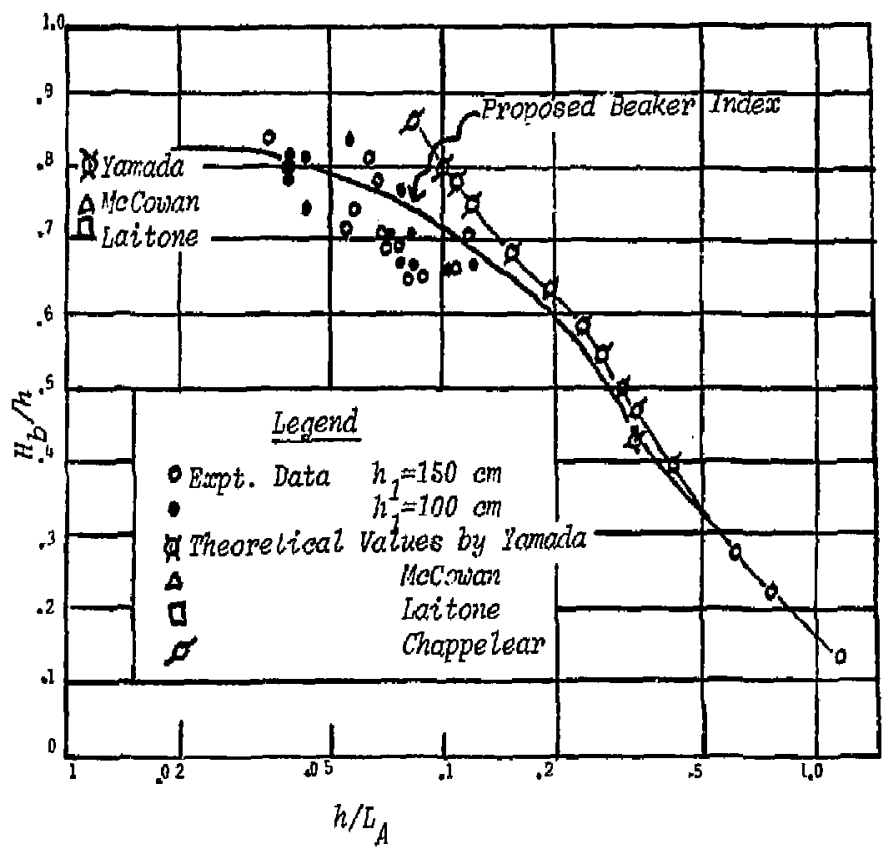

Fig. 3.1-Relative breaking wave height $\mathrm{Ib} / \mathrm{hb} / \mathrm{s}$. Telative Depth $h_{b} / I_{A} l$. 


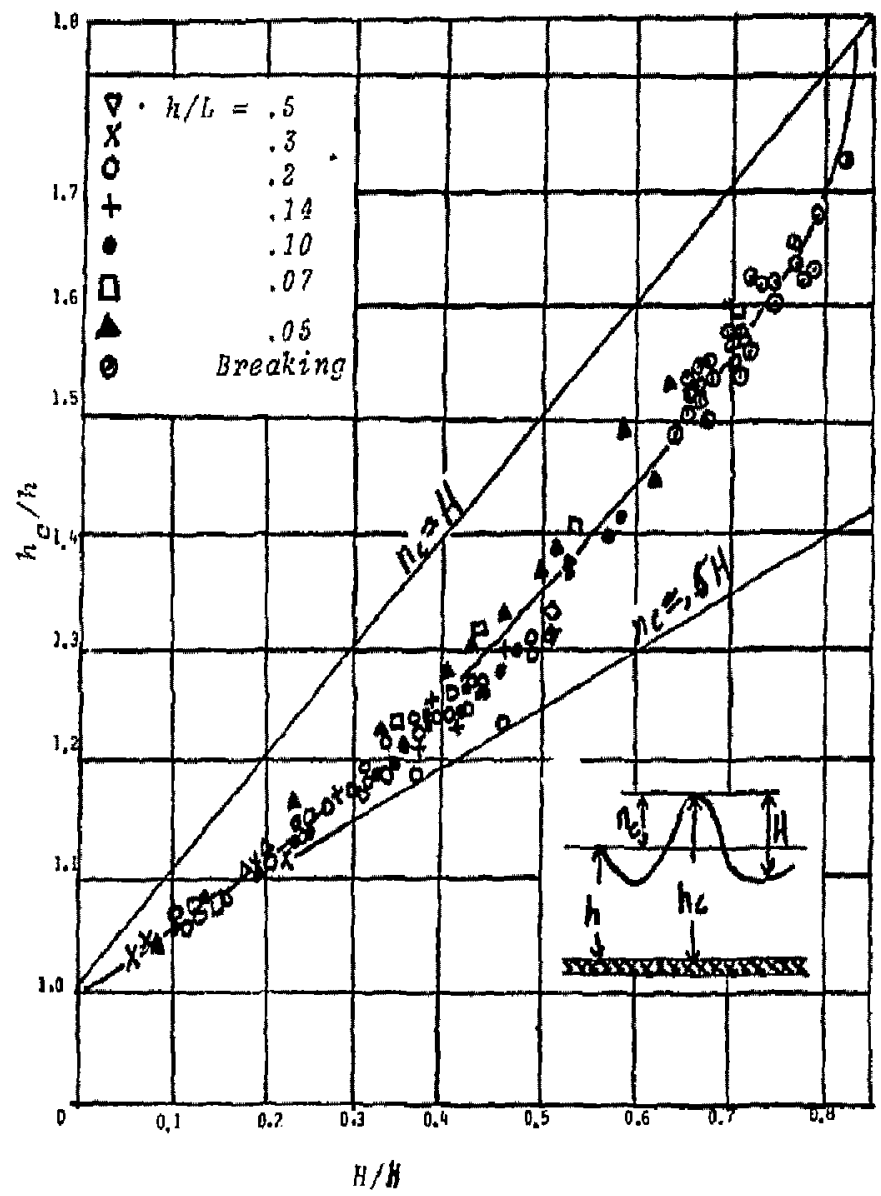

Fig. 8.2-Relative Height of iave Crest above Bottom $h_{c} / h$ vs. Relative llave lleight $\mathrm{H} / \mathrm{h}^{\mathrm{h}}$

C

$\boldsymbol{\epsilon}$

$\boldsymbol{c}$ 


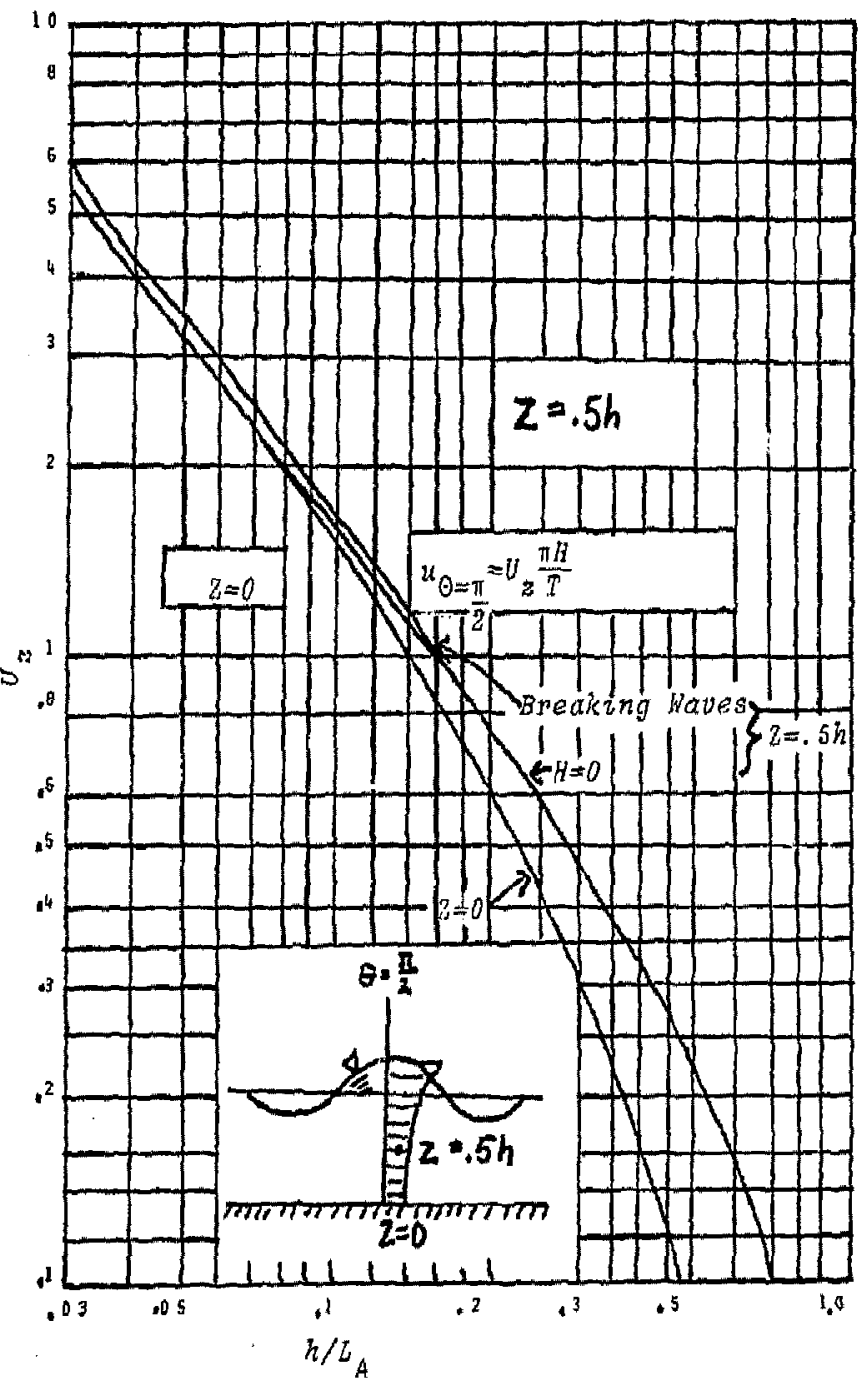

Figure 8.1.1-Design Diagram for orbital Velocity under "ave Crest at $z=0$ and $0.5 h^{\prime \prime}$

0 


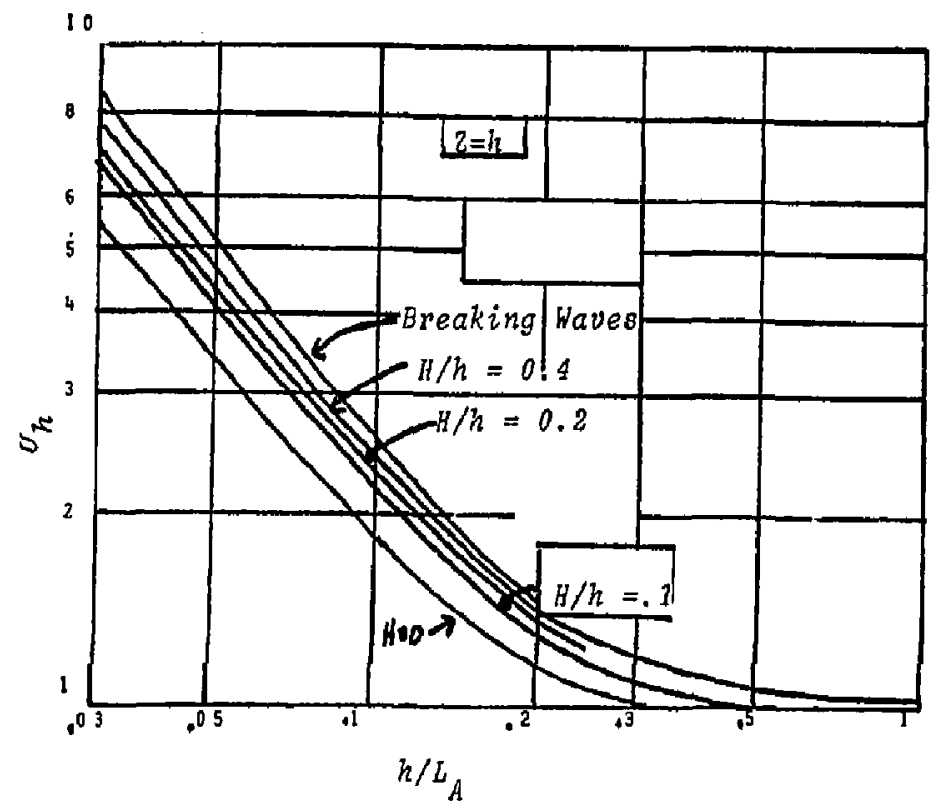

Figure 8.1.2-Design Diagram for Orbital Velocity under wave Crest at $z=h "$

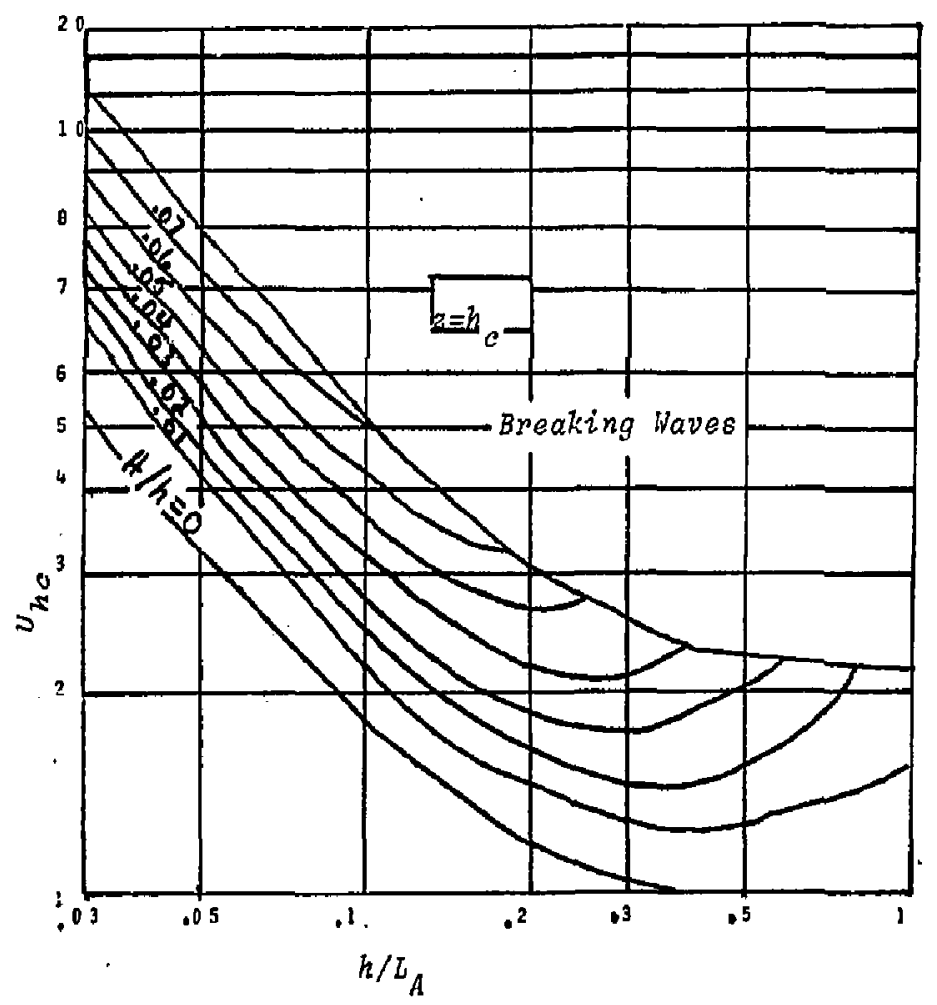

Figure 8.1.3-Design Diagram for Orbital velocity at Wave Crest $z=h_{c}$ 


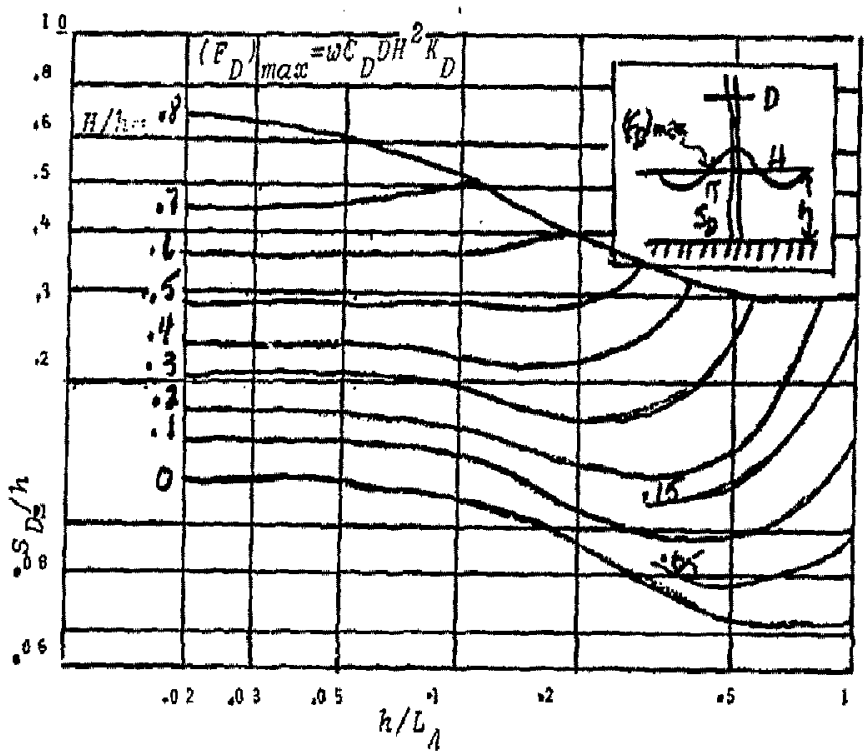
Figure 0.1.4-Drag Force Factor $k$ for a Uniform
Vertical Cylinter

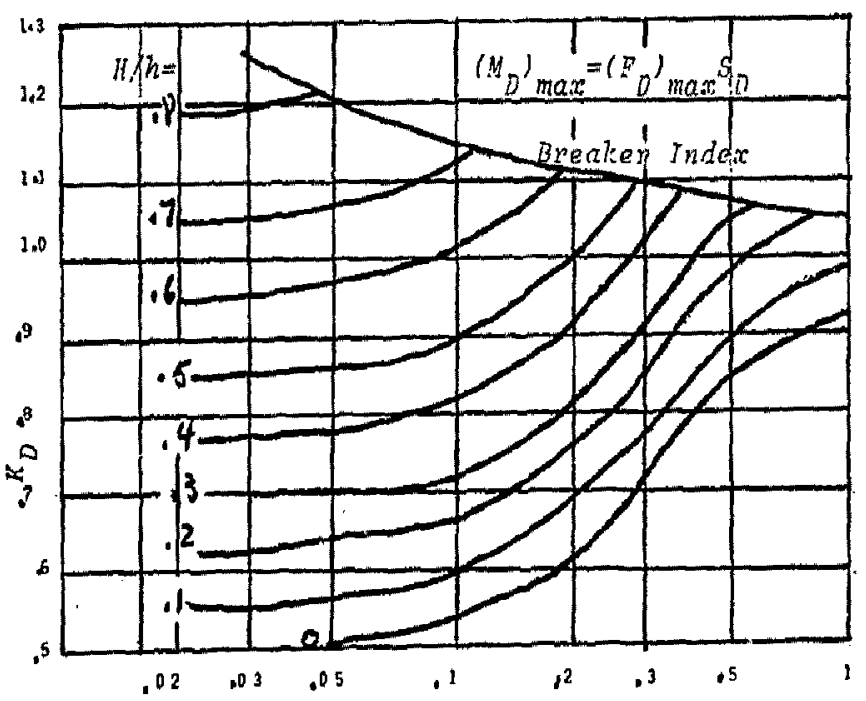

0

$$
B / L_{A}
$$
Figure 8.1.5-Effective Lever Arm $S$ for
Maximum Dra? Force" 
c.

$c$

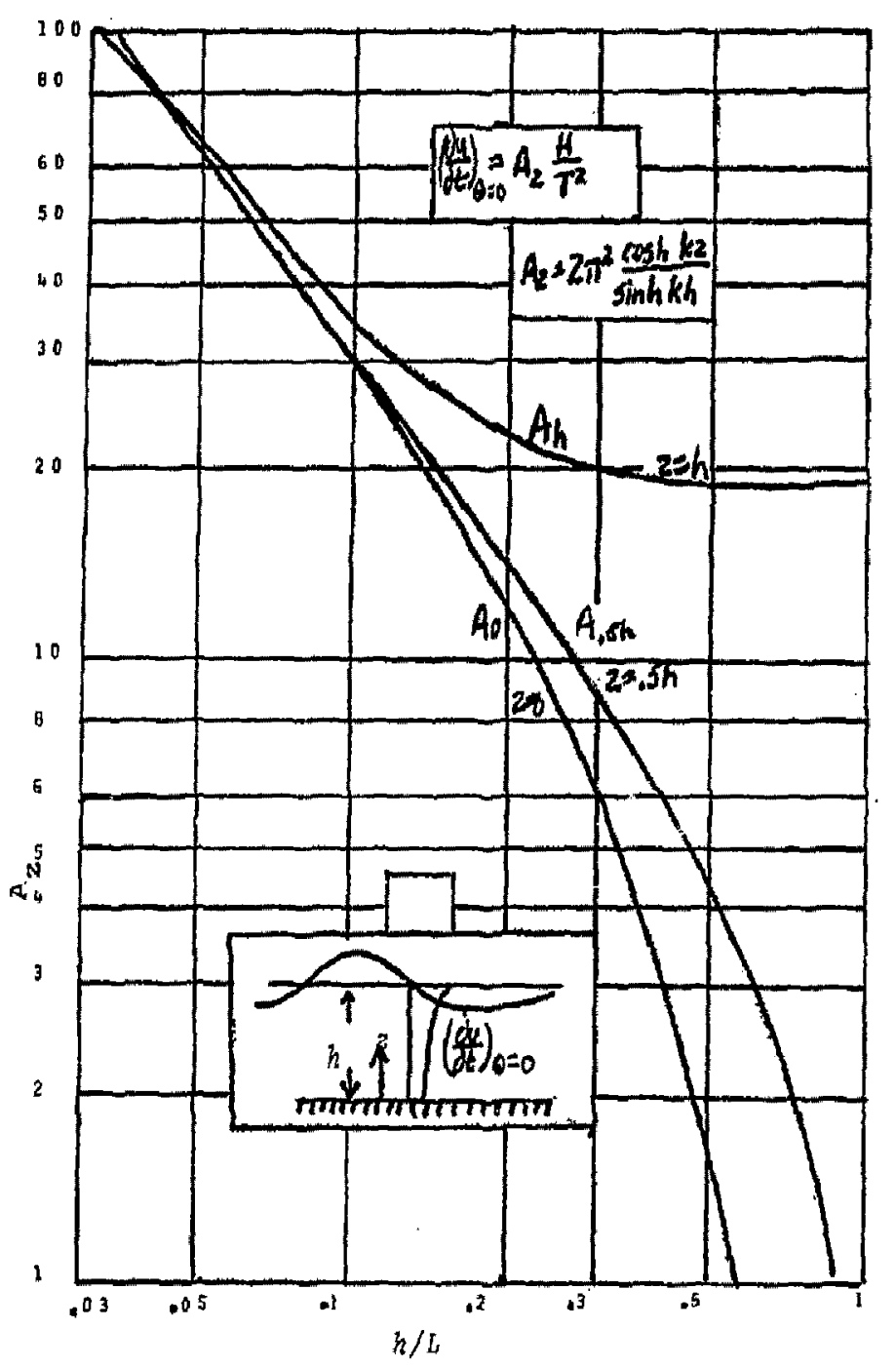

Figure 8.2.1-Design Diagram for Mater Particle Acceleration"

C 


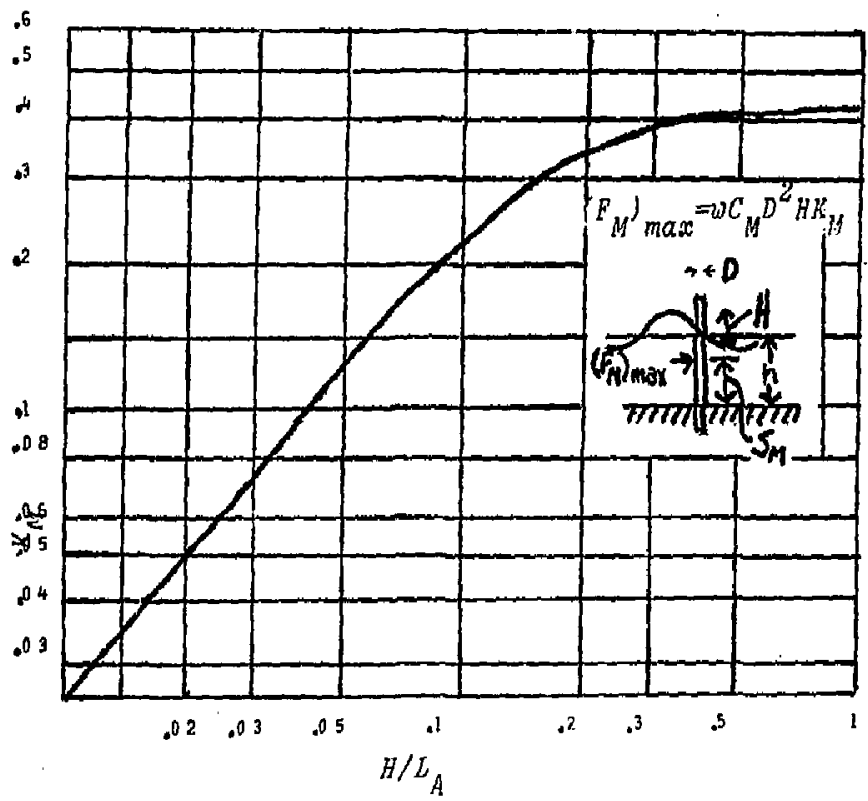

Pigure 8.2.2-Virtual Mass Force Factor $k_{p}$ for
a Uniform Vertical cylinder 


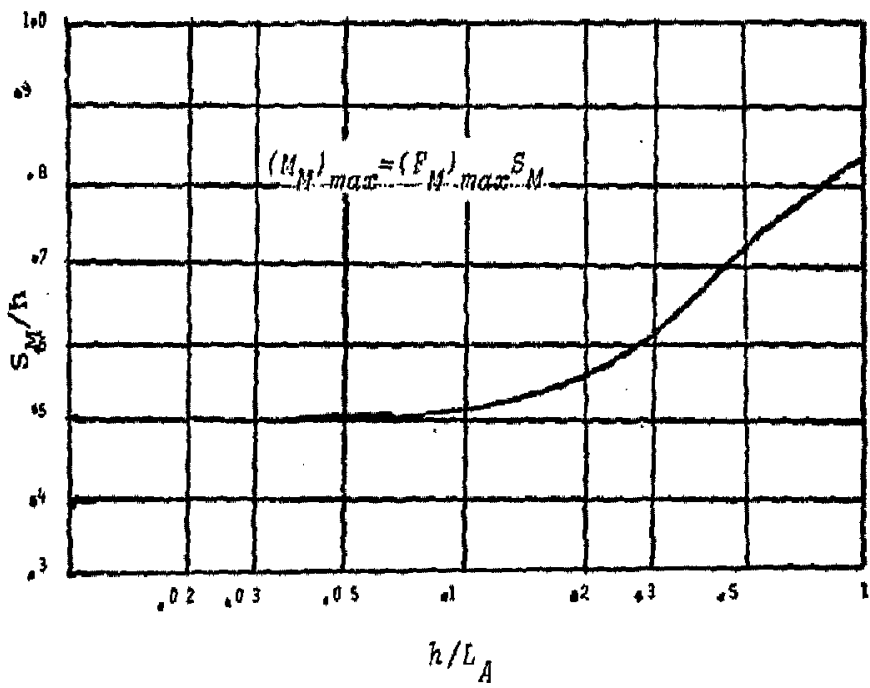
Figure 8.2.3-Effective Lever Arm $s_{M}$ for a Maximum
Virtual Mass Force"

c

$c$

C 